\title{
Erratum
}

\section{Erratum to: Nanopowders of gallium nitride GaN surface functionalized with manganese}

Michał Musiał ${ }^{1}$, Jacek Gosk ${ }^{2}$, Andrzej Twardowski ${ }^{3}$, Jerzy F. Janik ${ }^{1}$, and Mariusz Drygaś ${ }^{1, *}$

${ }^{1}$ Faculty of Energy and Fuels, AGH University of Science and Technology, al. Mickiewicza 30, 30-059 Krakow, Poland

${ }^{2}$ Faculty of Physics, Warsaw University of Technology, ul. Koszykowa 75, 00-662 Warsaw, Poland

${ }^{3}$ Faculty of Physics, Institute of Experimental Physics, University of Warsaw, ul. Pasteura 2, 02-093 Warsaw, Poland

Published online:

19 September 2016

(C) Springer Science+Business

Media New York 2016

Erratum to: J Mater Sci

DOI 10.1007/s10853-016-0317-6

The original article contains an incorrect version of Fig. 8 (the rectangular frames separating the $600^{\circ} \mathrm{C}$ derived samples from the $975{ }^{\circ} \mathrm{C}$-derived samples were missing). The correct Fig. 8 is displayed below.

The online version of the original article can be found under doi:10.1007/s10853-016-0317-6.

Address correspondence to E-mail: madrygas@agh.edu.pl 
Figure 8 Optical spectra for selected starting and respective Mn surface-functionalized GaN nanopowders. Top rectangular frame $600{ }^{\circ} \mathrm{C}$ derived samples, bottom rectangular frame $975{ }^{\circ} \mathrm{C}$ derived samples. Tangent lines in the Kubelka-Munk transformed spectra (right column) are to visualize determinations of electronic transition energies.
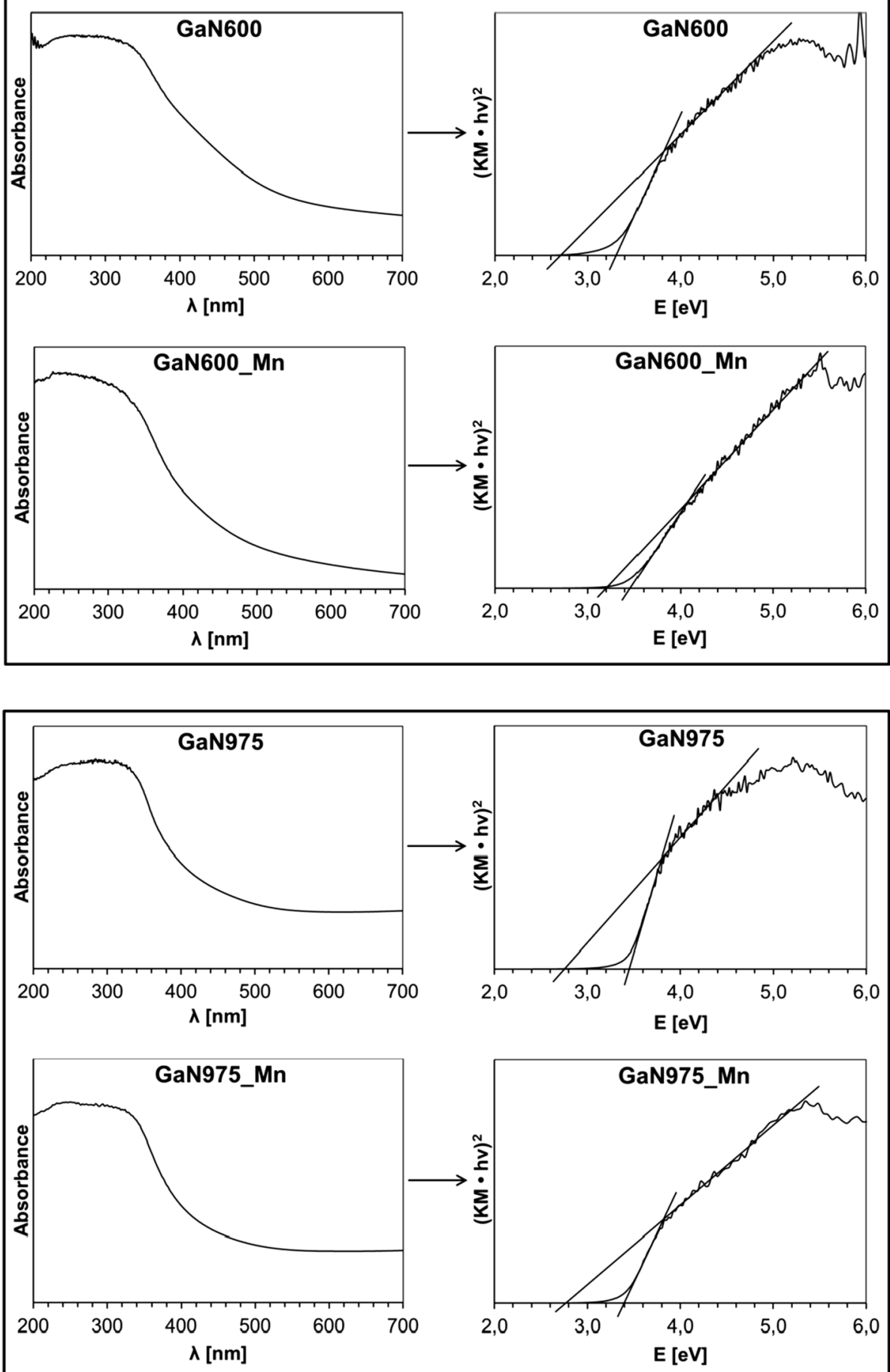